\title{
On the Treatment of Taxes in Cost-Benefit Analysis*
}

\author{
Per-Olov Johansson \\ Stockholm School of Economics and CERE
}

\begin{abstract}
In this note I discuss how to handle taxes in a cost-benefit analysis (CBA). In addition the shadow price of taxes in a CBA is related to the concepts of the marginal cost of public funds (MCPF) and the marginal excess burden (MEB) of taxes. Finally some estimates of the marginal cost of public funds for Spain and Sweden are reported and contrasted to an alternative approach to the treatment of taxes in a CBA.
\end{abstract}

JEL Classification: H21, H41, H43, Q51.

Keywords: cost-benefit analysis, marginal cost of public funds, excess burden, taxation.

\section{Resumen}

En esta nota se analiza cómo deben considerarse los impuestos en un análisis coste-beneficio $(A C B)$. Además, se estudia la relación de los precios-sombra de los impuestos utilizados en el ACB con los conceptos de coste marginal de los fondos públicos y el exceso de gravamen de los impuestos. Finalmente, se presentan algunas estimaciones del coste marginal de los fondos públicos para España y Suecia y se contrastan con un enfoque alternativo para el tratamiento de los impuestos en un análi sis coste-beneficio.

Palabras clave: análisis coste-beneficio, coste marginal de los fondos públicos, exceso de grava men, fiscalidad.

Clasificación JEL: H21, H41, H43, Q51.

\section{Introduction}

In a cost-benefit analysis of a public sector program one has to address the question how to treat taxes ${ }^{1}$. In a sense this seems straightforward although possibly very complicated to handle in the real world due to a lack of data and estimates of relevant price and income elasticities. There is also a huge literature on closely related issues like the marginal cost of public funds (MCPF) and the marginal excess burden (MEB) of taxes. The MCPF measures the welfare cost of raising an additional euro in the presence of distortionary taxation. The MEB is another kind of experiment where typically a hypothetical lump-sum payment is introduced. This payment keeps the individual on the same utility level as with a proposed increase in the income tax. According to Ballard and Fullerton (1992) one can speak of a Harberg-

* This paper was written for the Madrid seminar on Cost-Benefit Analysis (November 15-16, 2010). The paper draws on JOHANSSON and KRISTRÖM (2010). I am grateful to Ginés de Rus for providing me with some Spanish data.

${ }^{1}$ For an excellent introduction to cost-benefit analysis the reader is referred to DE RUS (2010). 
er-Pigou-Browning tradition or a MEB-tradition in which the marginal cost of public funds is always larger than unity and a Dasgupta-Stiglitz-Atkinson-Stern tradition or MCPF-tradition in which it may be larger or lower than one ${ }^{2}$.

Many recent studies have focused on redistributive issues, see, for example, Sandmo (1998) and Gahvari (2006) while others have focused on the provision of a public good in the presence of an income tax ${ }^{3}$. A typical result is that the studies confirm the Samuelson (1954) rule that the sum of consumers marginal willingnesses to pay for a public good should be equal to the marginal cost of providing the good. There is also an emerging literature on the MCPF concept in environmental economics where environmental taxation is analyzed in the presence of distortionary taxation; see, for example, Bovenberg and van der Ploeg (1994). For a full treatment of the concept of the MCPF the reader is referred to Dahlby (2008). Recent contributions by Gahvari (2006) and Kreiner and Verdelin (2011) address the MCPF concept within a Mirrlees (1971) second-best framework with heterogenous agents. However, it is difficult to see if the results are useful for applied cost-benefit rules and the approach is therefore not further discussed in this note. The same holds true for the highly abstract shadow prices derived by Drèze and Stern (1987); it is difficult to see how to apply these prices in a real world cost-benefit analysis.

The purpose of this note is modest. Drawing on Johansson and Kriström (2010) I present a simple cost benefit rule that can be used to assess small increases in the provision of a public good under alternative tax regimes (lump sum, ad valorem, and income taxes). It is demonstrated that these rules can be designed so as to resemble the MCPF, at least when producer prices remain unchanged by the considered marginal projects. It is also shown that one plus the marginal MEB (i.e. $1+\partial M E B / \partial t_{\mathrm{i}}$, where $t_{\mathrm{i}}$ is a tax) is equal to MCPF. This result implies that computable general equilibrim models can be used to estimate the marginal cost of public funds for different tax instruments. I also propose a slightly different design of cost-benefit rules that might be easier to estimate than the MCPF. An appendix addresses the definition of MCPF and the treatment of taxes in a multi-individual society.

\section{Some simple cost-benefit rules for a tax-distorted economy}

The point of departure for the analysis is the simplest possible, namely a singleindividual society or Robinson Crusoe economy ${ }^{4}$. This single individual is producer as well as consumer and also runs the public sector, treating all prices as unaf-

2 The literature is huge but important contributions include DIAMOND and MIRRLEES (1971), HARBERGER (1971), STIGLITZ and DASGUPTA (1971), ATKINSON and STERN (1974), HATTA (1977), MAYSHAR (1991), SNOW AND WARREN (1996), LIU (2004), and SLEMROD and YITZHAKI (2001).

3 The early contributions assumed a linear income tax; see, for example, CHRISTIANSEN (1981), HANSSON (1984), STUART (1984), FULLERTON (1991) and BALLARD and FULLERTON (1992).

4 The multi-individual case is partially addressed in the Appendix. 
fected by his or her actions. The public sector produces a single public good, e.g. a road or a railway, using homogeneous labor and a good as inputs. Revenues are generated by an ad valorem tax, which could be interpreted as a value added tax (VAT) in a multi-commodity variation of the model, a proportional tax on wage income, and the government might also use a lump-sum instrument to balance the budget (and there is also an untaxed numéraire commodity whose price is set equal to unity). Marginally changing the level of production of the public good generates a social cost-benefit rule for a tax-distorted economy.

The government's annual budget constraint is written as follows:

$$
T=t \cdot p \cdot x+t_{w} \cdot w \cdot l-p \cdot x^{g}-w \cdot l^{g}
$$

where $T$ is a lump-sum payment, $t$ is an ad valorem tax, $p$ is the producer price, $x$ is the private-sector equilibrium quantity of the commodity (but $p$ and $x$ could be interpreted as vectors and $t$ as the uniform VAT), $t_{w}$ is a wage tax, $w$ is the wage rate, $l$ is equilibrium employment, $x^{g}$ is the government's demand for the good to be used in the production of the public good, and $l^{g}$ is its demand for labor used in producing the public good (and there is a throughout suppressed untaxed numéraire good whose price is normalized to unity).

I will make no attempt to derive the social cost-benefit rule for a small or marginal change in the provision of the public good, but a slightly simplified variation is derived in Johansson and Kriström (2010). It is just claimed that the rule, expressed as a net present value rule, reads:

$$
N P V=\left(W T P+r^{N} \cdot \frac{\beta}{1+\alpha^{i}}\right) \cdot d g-\frac{1}{1+\alpha^{i}} \cdot C
$$

where WTP is the present value willingness to pay for the public good per additional unit, $d g$ is the number of units of the public good the project delivers, $r^{N}$ is the present value of an annual euro during the life span of the project ${ }^{5}, \beta$ and $\alpha^{i}$ for $i=T, t, t_{w}$ are (for simplicity time invariant) «correction» factors relating to the tax wedges in equation [1], and $C$ is the present value cost of the project (where goods used up are valued at producer prices).

The reason for the $\beta$-term in equation [2] is the fact that a change in the provision of the public good might affect the tax wedges in equation [1]. That is, the public and the private good might be complements or substitutes so that the quantity of the private good changes as $g$ is changed. If so the magnitude $t \cdot p \cdot x$ of is affected. Or employment might change as $g$ is changed implying that $t_{w} \cdot w \cdot l$ changes. The factor $\beta$ captures this kind of induced changes; see the appendix for some details. In a similar fashion $\alpha^{i}$ captures the impact of a tax increase $\left(i=T, t, t_{w}\right)$ on the tax wedges in equation [1]; see the appendix for a formal definition of $\alpha^{i}$. Recall that at least one tax

\footnotetext{
${ }^{5} r^{N}=\Sigma_{S}(1+r)^{-S}$, where $r$ is the social discount rate.
} 
must be increased in order to finance the considered project. It should be stressed that it is assumed that the government changes a tax in such a way that the budget balances. Thus we abstract from endogenous «spending effects», where $t$ or $t_{w}$ or is changed and $T$ then adjusts so as to balance the budget. After all, it is often claimed that lump-sum taxation is unavailable to real world decision-makers. However, it is straightforward to add endogenous «spending effects» to the $\alpha^{t}$-terms of distortionary taxes.

In terms of the marginal cost of public funds it can be shown that $M C P F^{i}=1 /$ $\left(1+\alpha^{i}\right)$ while $\beta$ is closely related to the marginal benefit of a public good (MBPG). $\mathrm{MCPF}$ expresses the monetary welfare cost of an additional euro in tax revenue. The reader is referred to the appendix for formal definitions of the concepts of MCPF and MBPG. From the expression $M C P F^{i}=1 /\left(1+\alpha^{i}\right)$ one can imagine that the marginal cost of public funds can be larger than, equal, or smaller than unity depending on how tax wedges are affected by a tax increase. For example, if employment is stimulated by an increase in a tax it is not unlikely that $M C P F^{i}<1$. In the absence of distortionary taxation, however $M C P F^{T}=1$, implying that Samuelson's classical result applies. In other words, the public good should be provided in such an amount that the (sum of the) marginal willingness to pay is equal to the marginal cost of providing the cost; see Samuelson (1954) for details. In terms of equation [2] $g$ should be such that $W T P \cdot d g-C=0$.

In the special case in which the utility function is weakly separable in the public good the $\beta$-term vanishes ${ }^{6}$ and we obtain a simple rule according to which one should compare the marginal willingness-to-pay for the project with its direct cost multiplied by a factor reflecting the impact of the project on marginal deadweight losses. The cost-benefit rule reduces to:

$$
N P V=W T P \cdot d g-\frac{1}{1+\alpha^{i}} \cdot C
$$

Thus the project's costs should be multiplied by the marginal cost of public funds. This approach is widely suggested in the literature on cost-benefit analysis and in manuals or cookbooks on how to undertake a real world cost-benefit analysis. However, it is important to underscore that the approach draws on the separability assumption. The practical problem is to estimate the different cross-derivatives of the $\beta$-term. To my knowledge no such estimates are currently available. Moreover, there seems to be no reason to assume that the $\beta$-term is the same for different projects. For example, why should a railway and reduced emissions of have the same impacts on tax wedges? On the other hand, if the projects are equally costly one can reasonably assume that they have the same MCPF.

Finally, a problem with the approach should be stressed. If the project affect prices, which typically is the case since the small project shifts the economy from one general equilibrium to another, it becomes even more complicated to estimate

\footnotetext{
${ }^{6}$ A utility function is weakly separable in $g$ if it can be written as $U=U[f(x, l), g]$.
} 
$1 /\left(1+\alpha^{i}\right)$ and $\beta$ since the effects of induced price changes must be accounted for. Moreover, the conventional definition of MCPF, see the appendix, becomes «contaminated»' since some induced price effects are contained in the denominator while others are contained in the numerator. The reader is referred to Johansson and Kriström (2010) for details.

\section{On the marginal excess burden of taxes}

Measures of the marginal excess burden of taxes are typically formulated in terms of an equivalent variation, see, for example, Fullerton (1991):

$$
M E B^{E V}=\frac{E V-\Delta R}{\Delta R}=\frac{E V}{\Delta R}-1
$$

where $E V$ is the equivalent variation associated with a tax change, and $\Delta R$ is the change in tax revenue; below these measures are defined. Stuart (1984) and others estimate such measures ${ }^{7}$. This kind of experiment is quite different from the MCPFexperiment. The MEB concept replaces a hypotethical increase in a distortionary tax by a hypothetical lump-sum payment while the MCPF, as mentioned above, captures the monetary welfare cost of collecting an additional euro in taxes. Nevertheless, if the MEB concept is applied in a cost-benefit analysis the relevant approach is to multiply direct project costs by one plus the MEB.

In order to shed some further light on the interpretation of the marginal excess burden of an income tax we use the following single-period equality to implicitly define $E V$ :

$$
V\left(p \cdot(1+t), \mathrm{w} \cdot\left(1-t_{w}^{0}\right), T-E V, g\right)=V\left(p \cdot(1+t), w \cdot\left(1-t_{w}^{1}\right), T, g\right)
$$

where superscript $1(0)$ refers to the final (initial) income tax level. Thus the individual is willing to pay at most $E V$ (in terms of lump-sum income) in order to «escape» the tax increase. A more general approach would allow prices to adjust following the change in the wage tax. Such general equilibrium measures can be estimated if a computable general equilibrium (CGE) model is available.

The ratio stated in equation [4] can be defined by calculating the initial and final tax revenues ${ }^{8}$ :

$$
\Delta R=t_{w}^{1} \cdot l^{1}-t_{w}^{0} \cdot \mathrm{w} \cdot l^{0}
$$

7 STUART (1984) uses the compensating surplus (CS), where supply of labor is kept constant following a change in the income tax.

8 I follow FULLERTON (1991), see his Figure 1, in referring the tax change to the income tax only (but note that in that figure actual labor supply is left unchanged by the considered tax change). Moreover, there are other views of what is the relevant measure of the change in tax revenue. The reader is referred to FULLERTON (1991) for details. 
where the superscript $1(0)$ refers to the final (initial) levels of labor supply and tax rate.

Equations [4] and [5] suggest that the concept of the MEB is distinctly different from the MCPF concept, unless in special circumstances as discussed by Fullerton (1991). As pointed out by Gahvari (2006) drawing on Auerbach and Hines (2002), the MEB refers to hypothetical lump sum payments/compensations that allows the individual to remain at a particular utility level. The MCPF, on the other hand, aims at capturing the actual changes in deadweight losses that a project causes.

However, the MCPF concept refers to a marginal increase in a tax rate. Therefore the relevant comparison is to a MEB-measure referring to a marginal tax increase. Johansson and Kriström (2010) show that

$$
1+\partial M E B / \partial t_{w}=M C P F^{t_{w}}
$$

where $M C P F^{t_{w}}$ refers to the case in which the wage tax is marginally increased; see the Appendix for some details. Thus for small tax changes the concept of the marginal excess burden has a meaningful interpretation also in terms of a cost-benefit analysis.

In fact, the equality between one plus the margianal MEB and MCPF holds for a small increase in any of the taxes used in the considered economy. This result opens up the possibility to use CGE models to estimate $1+\partial M E B / \partial t_{i}=M C P F^{t i}$, where $t_{i}$ refers to the tax that is used to finance a particular project, and the tax vector might be quite complex, i.e. there are many different tax instruments. Thus one could come up with a vector of MCPFs from which to select the most relevant or likely way of financing the considered project.

\section{An alternative way of treating taxes in a CBA}

In this section I introduce an alternative way of handling taxes in a cost-benefit analysis. It is a simple attempt to look for reasonable shortcuts when detailed estimates of the marginal cost of public funds are lacking. It is simple to implement and covers both the MCPF and $\beta / M C P F$. This approach relates taxes to what production or factor uses are crowded out by the considered project. For example, laborers that are drawn from other production activities are associated with an opportunity cost equal to $w \cdot(1+t)$ since this is the amount consumers ultimately are willing to pay for the commodities produced by the marginal worker. Similarly, laborers that would otherwise stay outside the labor force are now valued at their reservation wage, i.e., $w \cdot\left(1-t_{w}\right)$. This approach could be used in a sensitivity analysis of a project's social profitability.

This alternative way of stating the cost-benefit rule, used in Johansson and Kriström (2010), yields:

$$
N P V=W T P \cdot d g-C+\left(t \cdot p \cdot d x+t_{w} \cdot w \cdot d l\right) \cdot R^{N}
$$


where $d x$ is total annual change in final use of the commodity, $d l$ is total annual change in employment, and both entities, for expositional simplicity, are assumed to be constant over time. Note that this approach incorporates both the $\alpha$-factor and the $\beta$-factor in equation [2].

One extreme assumption is that labor supply is infinitely elastic so that employment increases by the amount needed for the project (direct labor plus labor needed for input goods and investment goods). Then $d x=0$ while $d l>0$ in equation [8]. In this case the suggestion is to multiply costs by a factor:

$$
a=\frac{w \cdot\left(1-t_{w}\right)}{w}
$$

In this case a reasonable lower bound for costs would be:

$$
C^{L B}=a \cdot C
$$

so that $N P V=W T P \cdot d g-a \cdot C$. Thus in this case costs would reflect the reservation wage. In both Spain and Sweden the $\alpha$-factor might be around 0.7 as in Table $1^{9}$.

TABLE 1

ESTIMATED LOWER AND UPPER BOUNDS FOR A PROJECT'S COSTS IN SPAIN AND SWEDEN

\begin{tabular}{|l|c|c|}
\hline \multicolumn{1}{|c|}{ Country } & Lower Bound & Upper Bound \\
\hline Spain & $C \cdot 0.7$ & $C \cdot 1.18$ \\
\hline Sweden & $C \cdot 0.7$ & $C \cdot 1.25$ \\
\hline
\end{tabular}

If aggregate employment remains unaffected, i.e. if $d l=0$, the considered project crowds out other consumption in order to release labor and input goods. Consumers' valuation of these commodities is a factor $(1+t)$ higher than the marginal product of labor. Therefore as a reasonable upper bound for costs in this simple case is:

$$
C^{U B}=C(1+t)
$$

where $t$ can be interpreted as the VAT in the multiple commodities case so that $N P V=W T P \cdot d g-C \cdot(1+t)$. Thus we multiply the project cost by a factor 1.25 if

9 The gross wage is $w=w_{N} \cdot\left(1+t_{S}\right)$, where $w_{N}$ denotes the wage, and $t_{S}$ denotes social security fees (covering pensions and so on) typically amounting to almost 50\% in Sweden and around $30 \%$ in Spain. The factor $a$ in equation [9] assumes that $w$ is subject to income taxation of 30\%. The equation can easily be adjusted so as to reflect other assumptions with respect to social security fees, $e . g$. that they partly are pure taxes. 
the VAT is 25\% (using the general Swedish rate) or 1.18 (using the general Spanish rate) as in Table 1. The approach assumes that homogeneous labor is the sole factor but it should be possible to generalize so as to be able to handle multiple primary factors. Even if the economy is opened up for international trade the approach will work. If an input is imported export must sooner or later increase so as to restore the trade balance. In order to release resources for this purpose consumption valued at market prices is probably crowded out.

These bounds could be adjusted so as to reflect intermediate cases. For example, one could think of a project implemented in a depressed area where it is reasonable to multiply labor costs by a factor 0.7 while produced inputs might be manufactured in regions where it is more reasonable to multiply costs by a factor 1.25 or 1.18. Moreover, at the expense of increased complexity, the approach -just like the the approach described in section 2- can be adjusted so as to handle the case with multiple primary factors. Finally, it should be stressed that if prices adjust so as to maintain general equilibrium, equation [8] is still valid. One would just have to reinterpret the $d x$ and $d l$ terms in the equation since they must reflect also changes caused by changes in prices and wages.

TABLE 2

MARGINAL COST OF PUBLIC FUNDS IN BASE CASE SCENARIO FOR SPAIN AND SWEDEN

\begin{tabular}{|l|c|c|}
\hline \multicolumn{1}{|c|}{ Country } & Min & Max \\
\hline Spain & 0.82 & $\begin{array}{c}1.88 \\
(1.34)\end{array}$ \\
\hline Sweden & 0.78 & $\begin{array}{c}3.41 \\
(1.74)\end{array}$ \\
\hline
\end{tabular}

NOTE: Numbers in parentheses refer to the upper bound if an increase in the marginal income tax is excluded. SOURCE: KLEVEN and KREINER (2003).

It might be noted that a recent OECD-study, see Table 2, in the base scenario estimates the marginal cost of public funds to between 0.82 to 1.88 for Spain and between 0.78 and 3.41 for Sweden, where the higher figure in both cases refer to an increase in a progressive income tax. Excluding a progressive tax reform, the span narrows to 0.82-1.34 for Spain and to 0.78-1.74 for Sweden. Alonso-Carrera and Manzano (2003) use a dynamic general equilibrium model to estimate the MCPF for Spain. They estimate it to be $0.65-0.7$ for a lump-sum tax, around 1 for a consumption tax, 1.26-1.32 for a wage income tax, and to $1.74-2.90$ for a capital tax ${ }^{10}$. Thus with the exception of a capital income tax the results are not very different from the

\footnotetext{
10 See also GONZÁLEZ-PÁRAMO and SANZ SANZ (2004) for estimates for Spain.
} 
bounds reported in Table 1; however, it should be stressed that in contrast to the results in Table 1 estimates of MCPF and $1+$ MEB do not cover the term $\beta / M C P F$ in equation [2]. The most recent figures for Sweden are reported in Sørensen (2010). Using a «MEB-approach» and a dynamic model he estimates the Swedish $1+$ MEB to 1.16-1.35. This is comparable to the estimated upper bound in Table 1, although that figure reflects both $\mathrm{MCPF}$ and $\beta / M C P F$, i.e. is a more general measure in that sense.

\section{Concluding remarks}

In this note I have investigated whether the concept of the marginal cost of public funds is suitable for use in a conventional cost-benefit analysis. Indeed if all producer prices are assumed to be constant and preferences are weakly separable in the public good it is legitimate to multiply a small project's direct costs by a factor reflecting the MCPF. However, if the separability condition is not satisfied one must in addition account for the impact of the public good on the magnitude of the tax wedges. Moreover, if producer prices adjust -as they typically do also for a small project in a general equilibrium context- the MCPF will be extremely complicated to estimate since it now also contains effects in both numerator and denominator of the price adjustments caused by the project. On the other hand, in a conventionally formulated cost-benefit rule these induced effects net out.

I have also pointed at another formulation of the cost-benefit rule which provide reasonable upper and lower bounds for a project's social profitability. This approach is easier to implement than an estimate of the marginal cost of public funds. This is so because the MCPF approach requires estimates of quite involved price and income elasticities. It might be both time consuming and complicated to obtain all the data needed in such an exercise unless one simply choose to rely on rough macroeconomic estimates (where all data are aggregated to national averages).

\section{References}

[1] ALONSO-CARRERA, J. and MANZANO, B. (2003): Análisis dinámico del coste de bienestar del sistema impositivo español. Una exploración cuantitativa. Hacienda Pública/Española Revista de Economia Pública 167, pp. 9-31.

[2] ATKINSON, A. B. and STERN, N. H. (1974): Pigou, taxation and public goods. Review of Economic Studies 41, pp. 117-127.

[3] AUERBACH, A. J. and HINES, J. R. (2002): Taxation and economic efficiency. In A. Auerbach and M. Feldstein (Eds.), Handbook of Public Economics Vol 3, pp. 13491421. North-Holland, Amsterdam.

[4] BALLARD, C. L. and FULLERTON, D. (1992): Distortionary taxation and the provision of public goods. Journal of Economic Perspectives 6, pp. 117-131. 
[5] BOVENBERG, A. L. and VAN DER PLOEG, F. (1994): Optimal environmental policy, public finance and the labour market in a second-best world. Journal of Public Economics 55, pp. 349-390.

[6] CHRISTIANSEN, V. (1981): Evaluation of public projects under optimal taxation. Review of Economic Studies 48, pp. 447-457.

[7] DAHLBY, B. (2008): The Marginal Cost of Public Funds. Theory and Applications. The MIT Press, Cambridge, Mass.

[8] DE RUS, G. (2010): Introduction to cost-benefit analysis. Looking for reasonable shortcuts. Edward Elgar.

[9] DIAMOND, P. A., and MIRRLEES, J. A. (1971): Optimal taxation and public production I and II. American Economic Review 61, pp. 8-27 and 261-278.

[10] DRÈZE, J., and STERN, N. (1987): The theory of cost-benefit analysis. In A. Auerbach and M. Feldstein (Eds.), Handbook of Public Economics. North-Holland, Amsterdam.

[11] FULLERTON, D. (1991): Reconciling recent estimates of the marginal welfare cost of taxation. American Economic Review 81, pp. 302-308.

[12] GAHVARI, F. (2006): On the marginal cost of public funds and the optimal provision of public goods. Journal of Public Economics 90, pp. 1251-1262.

[13] GONZÁLEZ-PÁRAMO, J. M., and SANZ SANZ, F. J. (2004): Evaluando reformas fiscales mediante el coste marginal de los fondos públicos. Fundación BBVA, Bilbao.

[14] HANSSON, I. (1984): Marginal cost of public funds for different tax instruments and government expenditures. Scandinavian Journal of Economics 86, pp. 115-130.

[15] HARBERGER, A. (1971): Three basic postulates for applied welfare economics: An interpretive essay. Journal of Economic Literature 9, pp. 785-797.

[16] HATTA, T. (1977): A theory of piecemeal policy recommendations. Review of Economic Studies 44, pp. 1-21.

[17] JOHANSSON, P.-O., and Kristrom, B. (2010): A note on cost-benefit analysis, the marginal cost of public funds, and the marginal excess burden of taxes. Environmental Economics, forthcoming.

[18] KLEVEN, J. H. and KREINER, C. T. (2003): The marginal cost of public funds in OECD countries: Hours of work versus labor force participation. CESIFO Working Paper 935.

[19] KREINER, C. T. and VERDELIN, N. (2011): Optimal provision of public goods: A synthesis. Scandinavian Journal of Economics, forthcoming.

[20] LIU, L. (2004): The marginal cost of funds and the shadow prices of public sector inputs and outputs. International Tax and Public Finance 11, pp. 17-29.

[21] MAYSHAR, J. (1991). On measuring the marginal cost of funds analytically. American Economic Review 81, pp. 1329-1335.

[22] MIRRLEES, J. A. (1971): An exploration in the theory of optimal taxation. Review of Economic Studies 38, pp. 175-208.

[23] SAMUELSON, P. A. (1954): The pure theory of public expenditure. Review of Economics and Statistics 36, pp. 387-389.

[24] SANDMO, A. (1998). Redistribution and the marginal cost of public funds. Journal of Public Economics 70, pp. 365-382.

[25] SLEMROD, J. and YITZHAKI, S. (2001). Integrating expenditure and tax decisions: The marginal cost of funds and the marginal benefit of projects. National Tax Journal 54, pp. 189-201. 
[26] SNOW, A. and Warren, R.-S. Jr. (1996): The marginal welfare cost of public funds: Theory and estimates. Journal of Public Economics 61, pp. 289-305.

[27] SØRENSEN, P. B. (2010): Swedish tax policy: Recent trends and future challenges. Report to the Swedish Expert Group on Public Economics. Report No. 2010:4.

[28] STIGLITZ, J. E. and DASGUPTA, P. (1971): Differential taxation, public goods and economic efficiency. Review of Economic Studies 38, pp. 151-174.

[29] STUART, C. (1984): Welfare costs per dollar of additional tax revenue in the United States. American Economic Review 74, pp. 352-362. 


\begin{abstract}
APPENDIX
In order to illustrate the concept of the marginal cost of public funds (in a single period model) I introduce the following Lagrangian:

$$
L=V\left(p \cdot(1+t), w \cdot\left(1-t_{w}\right), T, g\right)+\gamma \cdot N\left(T, t, t_{w}, g\right)
$$

where $V(\cdot)$ is an indirect utility function, $N(\cdot)=T-t \cdot p \cdot x-w \cdot t_{w} \cdot l+p \cdot x^{g}+w \cdot l^{g}$, $\gamma$ is a Lagrange multiplier, and the numéraire is suppressed. The aim here is to maximize social welfare subject to the government's budget constraint but I will not dig into the conditions for a second-best optimum; the reader is referred to Johansson and Kriström (2010) for some details. Let us instead consider a project financed by adjusting the ad valorem tax . Then, following Gahvari (2006) MCPF is defined as:
\end{abstract}

$$
M C P F^{t}=\frac{1}{\lambda} \cdot \frac{\partial V / \partial t}{\partial N / \partial t}
$$

where $\lambda$ is the marginal utility of (lump-sum) income ${ }^{11}$. Thus MCPF measures the monetary welfare cost of raising an additional euro in taxes. Using equation [A.1] one can show that $M C P F^{t}=1 /\left(1+\alpha^{t}\right)$, where

$$
\alpha^{t}=\left[\left(\frac{\partial x}{\partial q}\right) \cdot t \cdot p \cdot x^{-1}+t_{w} \cdot w \cdot \frac{\partial l}{\partial q} \cdot x^{-1}\right]
$$

with $q=p \cdot(1+t)$, i.e. the consumer price.

Similarly, one might define the marginal benefit of spending an additional euro on the public good, MBPG, as follows:

$$
M B P G=\frac{1}{\lambda} \cdot \frac{\partial V / \partial g}{\partial N / \partial g}
$$

Next, in order to arrive at the result on the marginal excess burden of taxes use the indirect utility function in equation [A.1] to define the MEB of a small increase in tax $i$ as $M E B^{t_{i}}=-\left(d E V^{t_{i}}+d N^{t_{i}}\right) \cdot\left(d N^{t_{i}}\right)^{-1}$, where $d E V^{t_{i}}=\lambda^{-1} \cdot\left(\partial V / \partial t_{i}\right) \cdot d t_{i}$ is the willingness-to-pay for escaping a small increase in $t_{i}$, and $-d N^{t_{i}}=-\left(\partial N / \partial t_{i}\right) \cdot d t_{i}$ is the change in total tax revenue caused by a ceteris paribus marginal increase in tax $t_{i}$; recall that taxes show up with a minus sign in in equation [A.1]. Then we arrive at the following result:

$$
1+M E B^{t_{i}}=-d E V^{t_{i}} / d N^{t_{i}}=\frac{1}{\lambda} \cdot \frac{\partial V / \partial t_{i}}{\partial N / \partial t_{i}}=M C P F^{t_{i}}
$$

11 At a (first-best or second-best) optimum it holds that $(\lambda)^{-1} \cdot\left(\partial V / \partial t_{i}\right) /\left(\partial N / \partial t_{i}\right)=\gamma / \lambda$. A partial derivative with respect to $t_{i}$ is interpreted as $\lambda$ and $\partial N / \partial T$ if $t_{i}$ is a lump-sum tax, as $-\lambda \cdot x^{d} \cdot p$ and $\partial N / \partial t$ if $t_{i}$ is a commodity tax, and as $-\lambda \cdot l^{S} \cdot w$ and $\partial N / \partial t_{w}$ if $t_{i}$ is a wage tax. 
where $M C P F^{t_{i}}$ is defined as in equation [A.2] with $t$ replaced by $t_{i}$. This paragraph is taken verbatim from Johansson and Kriström (2010). Alternatively, one could base the approach on the compensating variation, denoted $d C V$, since $d C V=d E V$ for marginal changes in e.g. taxes.

Finally I briefly consider an economy consisting of $H>1$ different individuals. Assume that the project under consideration is financed by uniform lump-sum taxation and that the social welfare function is Utilitarian so utilities can be summed across individuals. Moreover, consider a single-period variation. The welfare differential is written as follows:

$$
\begin{gathered}
d W=\sum_{h} \frac{\bar{\lambda}^{h}}{\bar{\lambda}}\left[V_{g}^{h} \cdot d g+\lambda^{h} \cdot d T\right]= \\
=\sum_{h} V_{g}^{h} \cdot d g+\bar{\lambda} \cdot\left[t \cdot p \cdot d x^{H}+t_{w} \cdot w \cdot d k^{H}-p \cdot d x^{g}-w \cdot d l^{g}\right]
\end{gathered}
$$

where $\bar{\lambda}$ is the expected or mean marginal utility of lump-sum income, a superscript $H(h)$ refers to an aggregate or total quantity (individual ), and the same decomposition is used as in section $4^{12}$. Rearranging and multiplying through by the expected marginal utility of income, equation [5] can be stated as:

$$
d W=\sum_{h} \frac{\bar{\lambda}^{h}}{\bar{\lambda}} \cdot W T P^{h}+t \cdot p \cdot d x^{H}+t_{w} \cdot w \cdot d l^{H}-p \cdot d x^{g}-w \cdot d l^{g}
$$

where $W T P^{h}=\left[V_{g}^{h} / \lambda^{h}\right] \cdot d g$ is individual $h^{\prime} s$ willingness to pay for the considered change in the provision of the public good. This WTP can be estimated using survey techniques like contingent valuation or choice experiments (conjoint analysis) or market based approaches like the travel cost method and the property value method. However, the problem is that the willingness-to-pay of each individual must be weighed using the individual's own marginal utility of lump-sum income relative to the average marginal utility of income. Unless the distribution of marginal utilities of income is relatively even across individuals, the sum of $W T P^{h}$ will be a poor predictor of society's valuation of the project in question, even in the special case of a Utilitarian social welfare function. It should be noted that with the exception of the $\lambda^{h} / \bar{\lambda}$-term, equation [A.6] contains the same terms as equation [8].

If a commodity tax or income tax is used to finance the project it is not possible to factor out the marginal utility of income in the way that is done in equation [A.5] since consumption and labor supply levels vary across individuals, in general. Therefore evaluation of the project's benefits and costs becomes very involved unless it is assumed that $\lambda^{h}$ is evenly distributed across individuals or $x^{h}$ is the same for all in the case of $d t>0$ or $l^{h}$ is the same for all in the case of $d_{w}>0$. In the last two cases, one can factor out $\bar{\lambda}$ in the same way as in equations [A.5] and [A.6]. Still, in these cases one faces the problem in valuing benefits discussed above.

\footnotetext{
12 Alternatively the cost-benefit rule can be expressed in terms of and $\alpha$ and $\beta$ as in section 2 .
} 